\section{RMD Open}

Rheumatic \&

Musculoskeletal Diseases

\title{
ACPA and RF as predictors of sustained clinical remission in patients with rheumatoid arthritis: data from the Ontario Best practices Research Initiative (OBRI)
}

To cite: Pope JE, Movahedi M Rampakakis E, et al. ACPA and RF as predictors of sustained clinical remission in patients with rheumatoid arthritis: data from the Ontario Best practices Research Initiative (OBRI). RMD Open 2018;4:e000738. doi:10.1136/ rmdopen-2018-000738

- Prepublication history and additional material for this paper are available online. To view these files, please visit the journal online (http://dx.doi. org/10.1136/rmdopen-2018000738).

Received 1 June 2018 Revised 6 September 2018 Accepted 12 September 2018

Check for updates

\section{(C) Author(s) (or their} employer(s)) 2018. Re-use permitted under CC BY-NC. No commercial re-use. See rights and permissions. Published by BMJ.

For numbered affiliations see end of article.

\section{Correspondence to}

Dr Janet E Pope;

janet.pope@sjhc.london.on.ca

\section{ABSTRACT}

Objective(s) This study evaluated the interaction of anticitrullinated protein antibody (ACPA) and rheumatoid factor (RF) in predicting sustained clinical response in an observational registry of patients with rheumatoid arthritis (RA) followed in routine practice.

Methods Patients with RA enrolled in the Ontario Best Practices Research Initiative registry, with $\geq 1$ swollen joint, autoantibody information and $\geq 1$ follow-up assessment were included. Sustained clinical remission was defined as Clinical Disease Activity Index (CDAl) $\leq 2.8$ in at least two sequential visits separated by 3-12 months. Time to sustained remission was assessed using cumulative incidence curves and multivariate cox regression. Results Among 3251 patients in the registry, 970 were included, of whom $262(27 \%)$ were $\mathrm{ACPA}^{\text {neg }} / \mathrm{RF}^{\text {neg }}, 60$ (6.2\%) ACPA $^{\text {pos }} /$ RF $^{\text {neg }}, 117$ (12.1\%) ACPA ${ }^{\text {neg }} /$ RF $^{\text {pos }}$ and 531 (54.7\%) ACPA ${ }^{\text {pos }} / \mathrm{RF}^{\mathrm{pos}}$ at baseline. Significant between group differences were observed in age $(p=0.02)$, CDAl $(p=0.03)$, tender joint count $(p=0.02)$ and Health Assessment Questionnaire $(p=0.002)$, with ACPA $^{\text {pos }}$ patients being youngest with lowest disease activity and disability. No difference in biologic use was found between groups (20.2\% of patients).

Over a mean follow-up of 3 years, sustained remission was achieved by $43.5 \%$ of $A C P A^{\text {pos }} /$ RF $^{\text {pos }}$ patients, $43.3 \%$ of $\mathrm{ACPA}^{\mathrm{pos}} / \mathrm{RF}^{\text {neg }}$ patients, $31.6 \%$ of $A C P A^{\text {neg }} / \mathrm{RF}^{\text {pos }}$ patients and $32.4 \%$ of $A C P A^{\text {neg }} / R F^{\text {neg }}$ patients $(p=0.01)$. Significant differences were observed in CDAl improvement based on ACPA and RF status where ACPA ${ }^{\text {pos }} / \mathrm{RF}^{\mathrm{pos}}$ had a shorter time to achieving sustained remission (HR 1.30; 95\% $\mathrm{Cl} 1.01$ to 1.67) and experienced significantly higher improvements compared with $A C P A^{\text {neg }} / \mathrm{RF}^{\text {neg }}$ patients. Conclusion(s) Combined ACPA and RF positivity were associated with improved and faster response to antirheumatic medications in patients with RA.

\section{INTRODUCTION}

Positive serology for anticitrullinated protein antibody (ACPA) and rheumatoid factor (RF)

\section{Key messages}

What is already known about this subject?

- There is uncertainty as to the effect of rheumatoid factor (RF) and anticitrullinated protein antibody (ACPA) on prognosis, which may or may not predict more severe disease, more erosion but possibly a better response to treatment.

- The incremental prognosis of both antibodies being positive in active established RA is unknown.

What does this study add?

- Using a large observational study of patients with RA followed in routine clinical care, this study has shown that combined ACPA and RF positivity may be associated with higher remission rate and greater improvement in disease activity during treatment with antirheumatic medications which seems to be driven by ACPA status rather than RF status.

How might this impact on clinical practice?

- This is a particularly relevant topic for rheumatologists seeing patients in routine clinical care and could inform decision-making in the management of patients with RA.

are included among the criteria for definitive rheumatoid arthritis (RA) diagnosis as per the 2010 American College of Rheumatology/ classification criteria for rheumatoid arthritis (RA). ${ }^{12}$ These autoantibodies may be predictive of the clinical disease course of RA. The literature is conflicted as to the impact of ACPA and RF on disease activity. Some studies have shown that positive $\mathrm{ACPA}^{34}$ and positive $\mathrm{RF}^{5-7}$ are associated with more active disease including radiographic progression ${ }^{89}$; whereas other studies have shown an association between positive ACPA and low clinical 
disease activity. ${ }^{5}{ }^{10}$ Immunoglobulin (Ig)A RF but not IgM RF (the latter is more commonly ordered) predict worse prognosis in early RA (ERA). ${ }^{11}$

There is uncertainty as to the effect of RF and ACPA on prognosis, which may or may not predict more severe disease, more erosion but possibly a better response to treatment. The incremental prognosis of both antibodies being positive in active established RA is unknown. Thus, the purpose of this study was to evaluate the impact of both ACPA and RF in predicting clinical response in a large observational study of patients with RA followed in routine clinical care and to determine if double-positive antibodies have a different effect on response to treatment compared with other combinations.

\section{METHODS}

\section{Data source and patients}

The Ontario Best Practices Research Initiative (OBRI) is a provincial registry that prospectively gathers long-term information on patients with RA followed in routine care. It incorporates physician assessments and a unique method of collecting data from the patients directly using telephone interviewers. Patients are eligible if they were $\geq 16$ years at the time of diagnosis and are $\geq 18$ years of age at the time of enrolment with a physician confirmed RA diagnosis and at least one swollen joint. Patients are recruited at any stage of disease and are managed as per the medical judgement of their rheumatologist. Most patients enrolled in the OBRI have prevalent longstanding RA.

Institutional research ethics approval was obtained prior to recruitment.

\section{Inclusion criteria}

Between January 2008 and January 2017, 3251 eligible and consented patients across 65 sites were participating in the OBRI registry. For this study, the analysis population was restricted to patients with RA with available autoantibody information (ACPA and RF status) and baseline Clinical Disease Activity Index (CDAI) information and at least one follow-up assessment (figure 1).

\section{Clinical and patient-reported data}

The clinical data collected during physician visits included: ACPA and RF status, patient global assessment (PtGA), physician global assessment (PhGA), 28-joint tender count (TCJ-28), 28-joint swollen count (SJC-28), RA medication use including conventional synthetic disease-modifying antirheumatic drugs, biologic disease modifying antirheumatic drugs and oral steroids. Patient-reported data collected by interviewers included: sociodemographic characteristics, Health Assessment

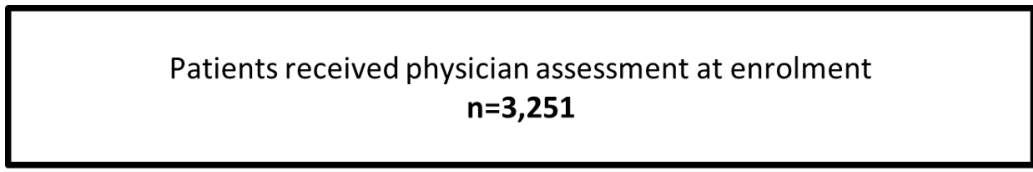

\section{Excluded:}

With only one physician visit $(\mathrm{n}=134)$

With CDAI missing at enrolment $(n=329)$

Patients with available information for ACPA $\underline{\mathrm{OR}} \mathrm{RF}$ at enrolment $\mathrm{n}=\mathbf{2 , 5 6 3}$

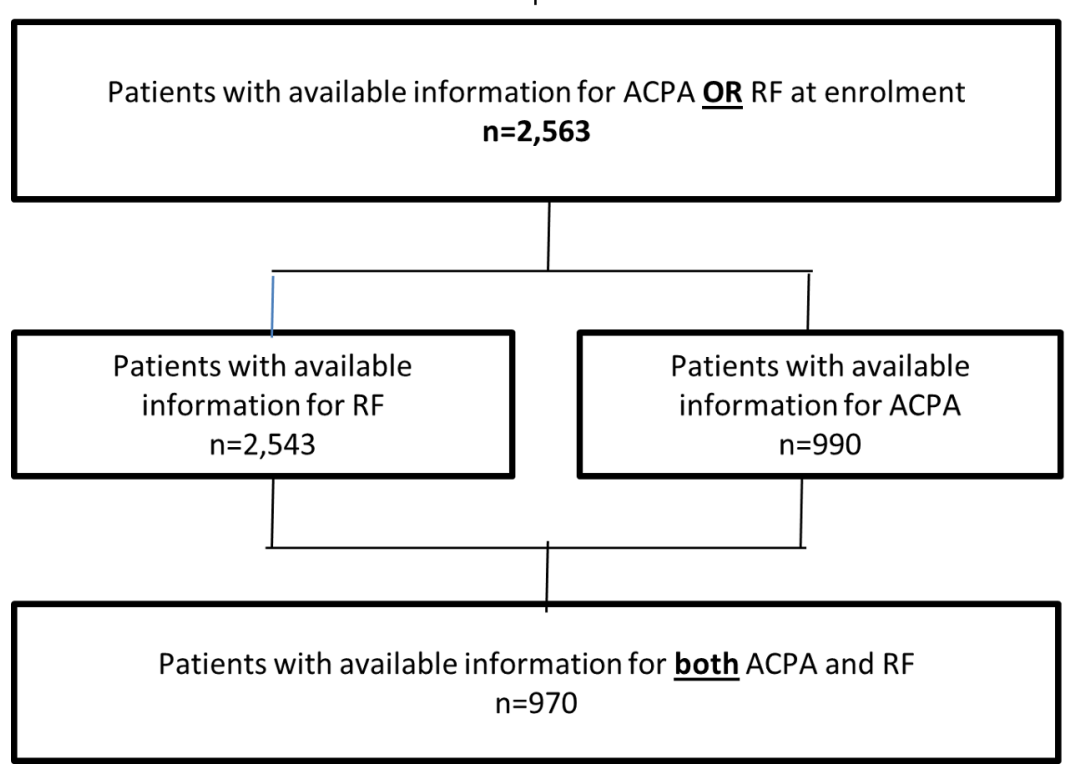

Figure 1 Cohort selection flow chart. 
Questionnaire Disability Index, Health Assessment Questionnaire Pain Index and comorbidity profile.

\section{Exposure definition}

ACPA and RF were considered as exposure and, based on their status, patients were classified into four groups: (1) $\mathrm{ACPA}^{\text {neg }} / \mathrm{RF}^{\text {neg; }}$; (2) $\mathrm{ACPA}^{\text {neg }} / \mathrm{RF}^{\text {pos }}$; (3) $\mathrm{ACPA}^{\text {pos }} / \mathrm{RF}^{\text {neg }}$ and (4) $\mathrm{ACPA}^{\mathrm{pos}} / \mathrm{RF}^{\mathrm{pos}}$.

\section{Outcome definition}

Primary outcome

CDAI was the disease activity measure of interest and was examined in two ways: (1) achievement of sustained remission, defined as at least two sequential visits, separated by at least 3 and up to 12 months, with CDAI $\leq 2.8$ (online supplementary figure 1) and (2) CDAI as continuous variable over time.

\section{Secondary outcomes}

In addition to CDAI, the associations between ACPA/ RF group and 28-joint Disease Activity Score-erythrocyte sedimentation rate (DAS28-ESR), Simplified Disease Activity Index (SDAI) and components of CDAI (SJC-28, TJC-28, PtGA, and PhGA) were investigated as secondary outcomes.

\section{Statistical analysis}

Descriptive statistics including the mean and SD for continuous variables and counts and proportions for categorical variables were produced. The analysis of variance or Kruskal-Wallis test, as appropriate, was used for the comparison of ACPA/RF groups for continuous variables and the $\chi^{2}$ or the Fisher's exact test, as appropriate, for categorical variables.

Cumulative incidence function was used to plot the probability of achieving first sustained remission over time and $p$ value of less than 0.05 was considered significant for the difference between estimates for the four $\mathrm{ACP} / \mathrm{RF}$ groups.

The primary analysis examined the association between ACPA/RF status and sustained remission using univariate and multivariate Cox proportional regression models. In the multivariate analysis, the association between ACPA/ RF status and first sustained remission was adjusted for age, sex and CDAI measure at baseline.

In a secondary analysis, the association between ACPA/ $\mathrm{RF}$ status at baseline and CDAI (as continuous variable) over time was examined using Generalised Linear Mixed Models (GLMMs) adjusted for age, sex, time and CDAI measure at baseline.

A tertiary analysis was also conducted to determine which component of the CDAI may drive any association between ACPA/RF status and disease activity. For this, each component of CDAI (SJC-28, TJC-28, PtGA, and PhGA) measured over time was evaluated for association with ACPA/RF status using GLMMs adjusted for age, sex, time and outcome measure at baseline. Two alternative measures of RA disease activity, SDAI and DAS28-ESR were also examined for association with ACPA/RF status.
Subset analysis

We conducted two subset analyses evaluating: (1) the association between ACPA/RF at baseline and CDAI over time in patients with early onset of disease (RA duration $\leq 1$ year since diagnosis) and (2) the individual association of ACPA status and RF status at baseline with CDAI over time. In the latter model, the statistical interaction of ACPA and RF was also examined.

\section{Sensitivity analysis}

Finally, a sensitivity analysis was performed for all multivariate analyses by generating two additional models considering various covariates that were significantly associated with the outcomes of interest in univariate analysis $(p<0.05)$ given that they might be confounding variables.

All statistical analyses were performed using SAS V.9.4.

\section{RESULTS}

A total of 970 patients were included in the analysis, of whom $262(27 \%)$ were $\mathrm{ACPA}^{\mathrm{neg}} / \mathrm{RF}^{\text {neg }}, 60(6.2 \%)$ $\mathrm{ACPA}^{\mathrm{pos}} / \mathrm{RF}^{\text {neg }}, 117(12.1 \%) \mathrm{ACPA}^{\text {neg }} / \mathrm{RF}^{\mathrm{pos}}$ and 531 $(54.7 \%) \mathrm{ACPA}^{\mathrm{pos}} / \mathrm{RF}^{\mathrm{pos}}$. At baseline, significant differences were observed between groups in age $(p=0.02)$, CDAI $(\mathrm{p}=0.03)$, tender joint count $(\mathrm{p}=0.02)$ and HAQ $(\mathrm{p}=0.002)$, with $\mathrm{ACPA}^{\mathrm{pos}} / \mathrm{RF}^{\mathrm{pos}}$ and $\mathrm{ACPA}^{\mathrm{pos}} / \mathrm{RF}^{\text {neg }}$ patients being youngest and having the lowest disease activity and disability (table 1). No differences were observed for current biologic use between groups which was reported in $20.2 \%$ of patients.

Over 3 years mean of follow-up, sustained remission was achieved by $231(43.5 \%)$ of $\mathrm{ACPA}^{\mathrm{pos}} / \mathrm{RF}^{\mathrm{pos}}$ patients, $26(43.3 \%)$ of $\mathrm{ACPA}^{\text {pos }} / \mathrm{RF}^{\text {neg }}$ patients, $37(31.6 \%)$ of $\mathrm{ACPA}^{\text {neg }} / \mathrm{RF}^{\mathrm{pos}}$ patients and $85(32.4 \%)$ of $\mathrm{ACPA}^{\text {neg }} /$ $\mathrm{RF}^{\mathrm{neg}}$ patients $(\mathrm{p}=0.01)$ (data not shown). Over time, significant differences were observed in cumulative incidence of achieving first sustained clinical response based on both ACPA and RF status ( $\mathrm{p}=0.004)$ (figure 2). Time to achieving first sustained remission was shorter in $\mathrm{ACPA}^{\mathrm{pos}} / \mathrm{RF}^{\mathrm{pos}}$ (median 3.7 years; 95\% CI 3.0 to 4.3 ) and $\mathrm{ACPA}^{\mathrm{pos}} / \mathrm{RF}^{\text {neg }}$ (median 3.4 years; 95\%) patients compared with $\mathrm{ACPA}^{\text {neg }} / \mathrm{RF}^{\text {neg }}$ patients (median 5.1 years; $95 \%$ CI 3.7 to 6.2 ) (figure 2).

\section{Association between ACPA/RF status and first sustained remission}

Table 2 summarises the results of the primary analysis assessing the association between baseline ACPA/RF status and time to achieving first sustained remission. After adjusting for potential confounders (age, sex and CDAI at baseline), a significant positive association was observed between $\mathrm{ACPA}^{\mathrm{pos}} / \mathrm{RF}^{\mathrm{pos}}$ and sustained remission (HR 1.30; 95\% CI 1.01 to 1.67 ; $\mathrm{p}=0.04$; table 2 ) compared with $\mathrm{ACPA}^{\mathrm{neg}} / \mathrm{RF}^{\mathrm{neg}}$. Higher CDAI (HR 0.97; 95\% CI 0.96 to $0.98 ; \mathrm{p}<0.0001$ ) and older age (HR $0.99 ; 95 \%$ CI 0.98 to $1.00 ; \mathrm{p}=0.01)$ at baseline were negatively associated with achievement of sustained remission (table 2). 


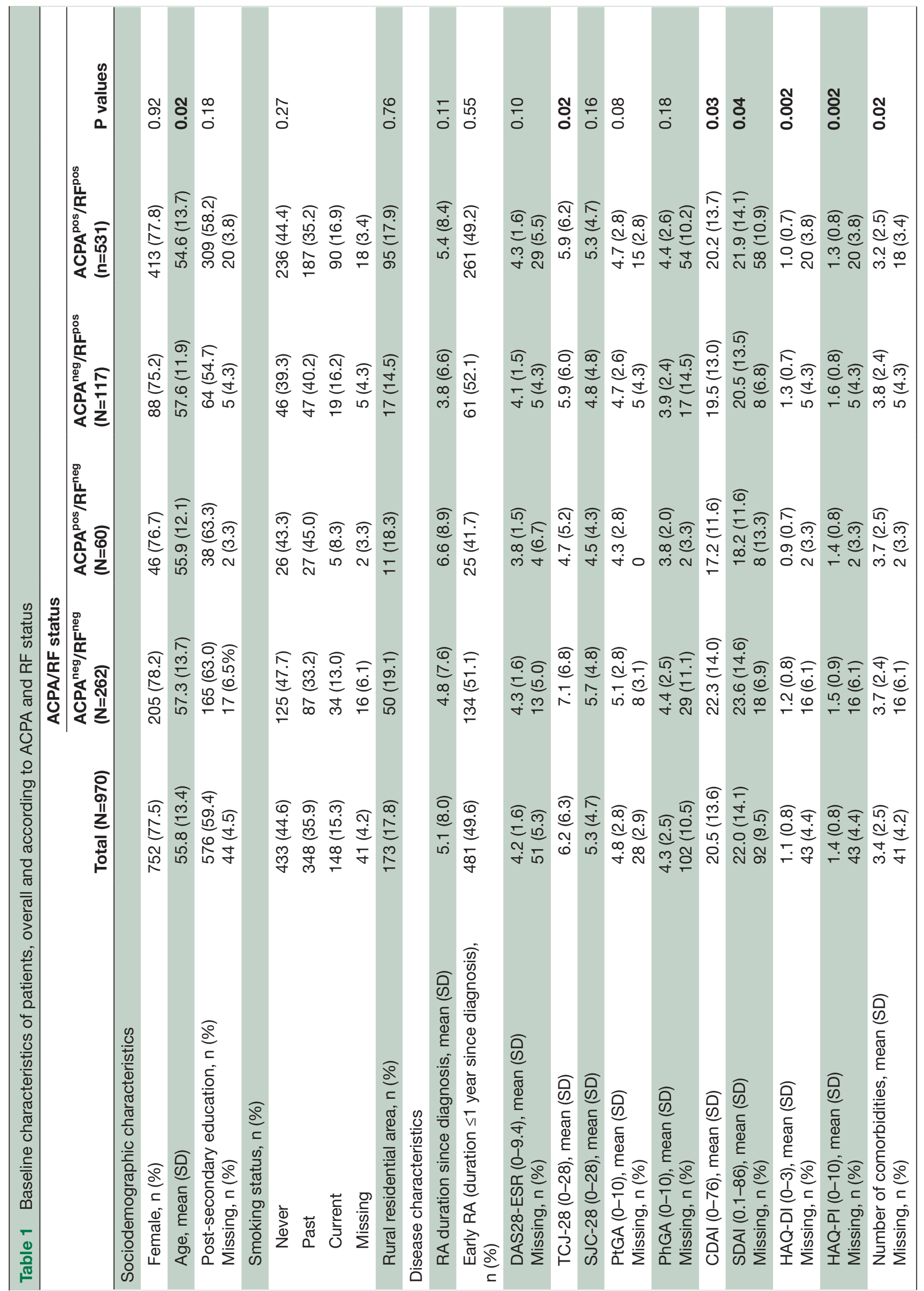




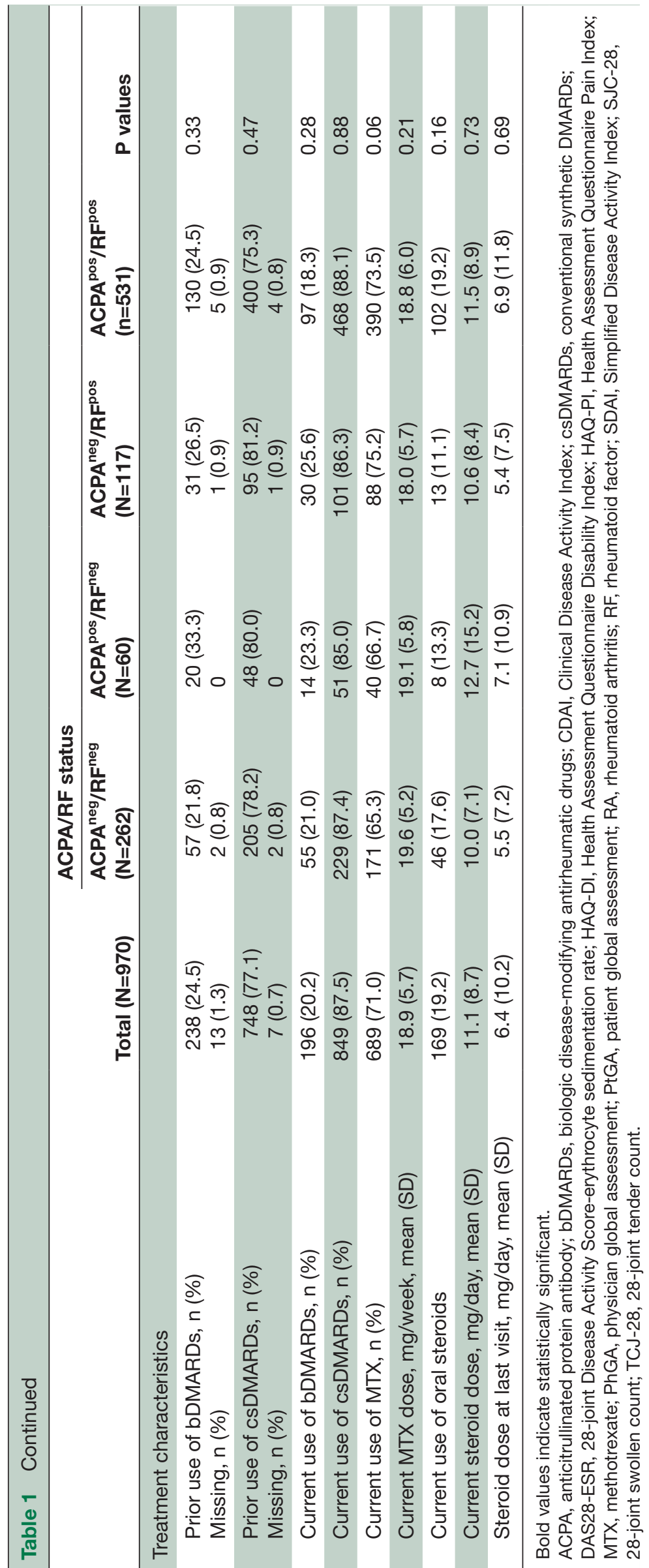




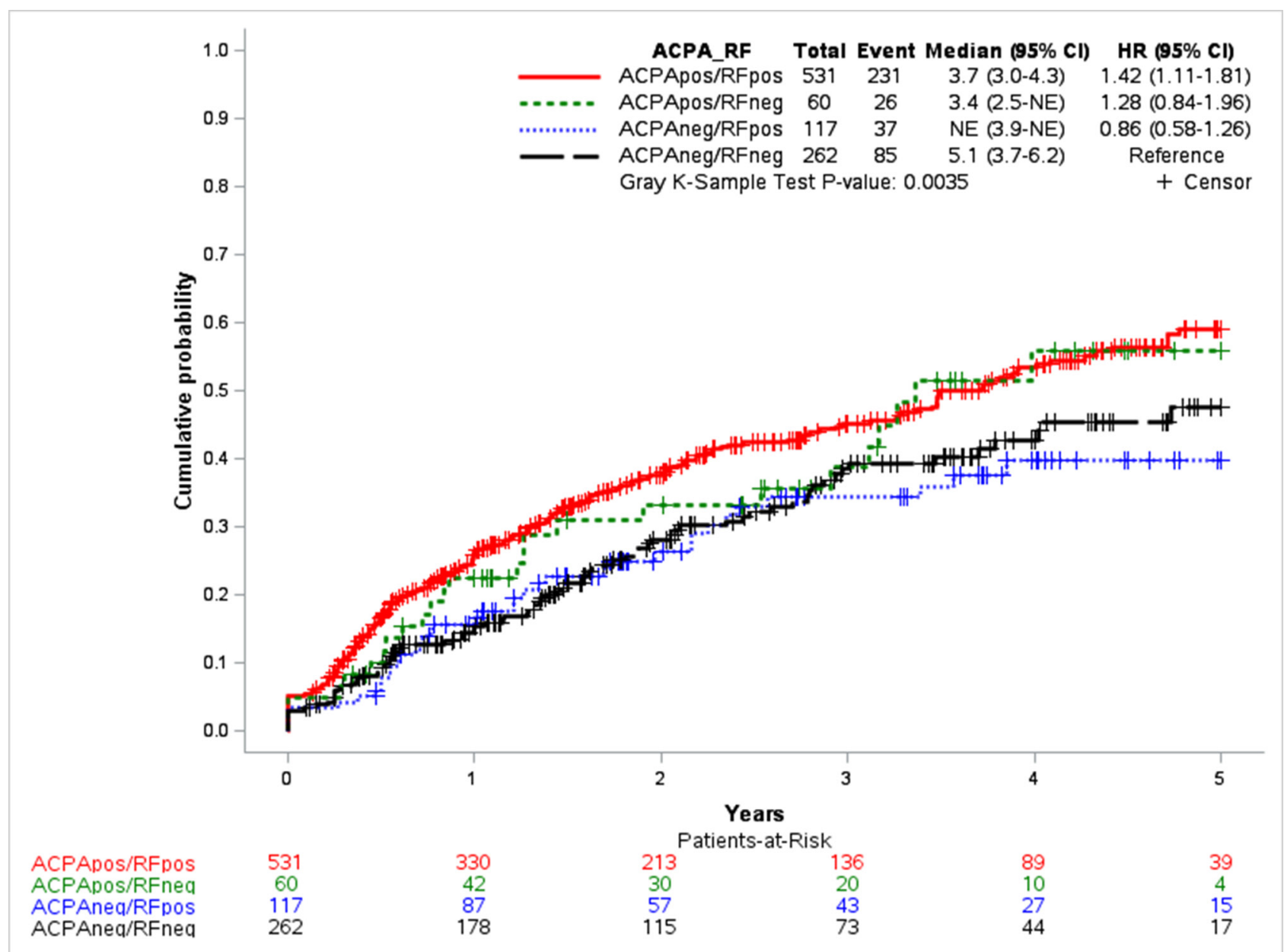

Figure 2 Cumulative hazard functions for first sustained remission by anticitrullinated protein antibody (ACPA)/rheumatoid factor (RF) status.

Association between ACPA/RF status and CDAl over time

Table 3 summarises the results of the secondary analysis assessing the association between baseline ACPA/RF status and CDAI over time. After adjusting for potential confounders (age, sex, CDAI at baseline and time), a significantly greater improvement in CDAI was observed in $\mathrm{ACPA}^{\mathrm{pos}} / \mathrm{RF}^{\mathrm{pos}}$ patients ( $\beta$ coefficient -1.63 ; SE 0.50 ; $\mathrm{p}=0.001)$ compared with $\mathrm{ACPA}^{\text {neg }} / \mathrm{RF}^{\text {neg }}$ patients. Female sex ( $\beta$ coefficient 1.91 ; SE $0.51 ; \mathrm{p}=0.0002)$ and higher CDAI at baseline ( $\beta$ coefficient 0.43 ; SE: $0.02 ; p<0.0001)$

Table 2 Association between ACPA/RF status at baseline and time to first sustained remission using Cox proportional hazards regression analysis

Hazard Ratio (95\% Confidence Interval), p-value

Unadjusted model Adjusted model

\section{ACPA status}

\begin{tabular}{|c|c|c|}
\hline $\mathrm{ACPA}^{\text {neg }} / \mathrm{RF}^{\text {neg }}$ & Ref & Ref \\
\hline $\mathrm{ACPA}^{\text {neg }} / \mathrm{RF}^{\text {pos }}$ & 0.86 (0.58-1.26), 0.26 & 0.82 (0.56-1.20), 0.31 \\
\hline $\mathrm{ACPA}^{\text {pos }} / \mathrm{RF}^{\text {neg }}$ & 1.28 (0.84-1.96), 0.44 & 1.16 (0.74-1.80), 0.52 \\
\hline $\mathrm{ACPA}^{\text {pos }} / \mathrm{RF}^{\text {pos }}$ & 1.42 (1.11-1.81), 0.01 & 1.30 (1.01-1.67), 0.04 \\
\hline Female & 0.96 (0.74-1.23), 0.73 & 0.85 (0.67-1.08), 0.19 \\
\hline Age at baseline & 0.99 (0.98-1.00), 0.02 & 0.99 (0.98-1.00), 0.01 \\
\hline CDAI at baseline & $0.97(0.96-0.98),<0.0001$ & $0.97(0.96-0.98),<0.0001$ \\
\hline
\end{tabular}

Adjusted model is adjusted for age, sex and CDAl at baseline.

Bold values indicate statistically significant.

ACPA, anticitrullinated protein antibody; CDAl, Clinical Disease Activity Index RF, rheumatoid factor. 
Table 3 Association between ACPA/RF status at baseline and CDAl over time using GLMMs

\begin{tabular}{|c|c|c|c|c|}
\hline & \multicolumn{4}{|c|}{ Regression coefficients (standard error), p-value } \\
\hline & \multicolumn{2}{|c|}{ All patients $(n=970)$} & \multicolumn{2}{|c|}{ Patients with early RA ( $n=481$ ) } \\
\hline & Unadjusted model & Adjusted model & Unadjusted model & Adjusted model \\
\hline \multicolumn{5}{|c|}{ ACPA status at baseline } \\
\hline $\mathrm{ACPA}^{\mathrm{neg}} / \mathrm{RF}^{\text {neg }}$ & Ref & Ref & Ref & Ref \\
\hline $\mathrm{ACPA}^{\text {neg }} / \mathrm{RF}^{\text {pos }}$ & $-1.19(1.01), 0.24$ & $0.48(0.73), 0.51$ & $-1.68(1.37), 0.22$ & $-0.33(1.01), 0.74$ \\
\hline $\mathrm{ACPA}^{\text {pos }} / \mathrm{RF}^{\text {neg }}$ & $-2.96(1.29), 0.02$ & $-0.63(0.94), 0.50$ & $-4.15(1.93), 0.03$ & $-1.72(1.44), 0.02$ \\
\hline $\mathrm{ACPA}^{\text {pos }} / \mathrm{RF}^{\text {pos }}$ & $-2.73(0.69),<0.0001$ & $-1.63(0.50), 0.001$ & $-3.00(0.95), 0.002$ & $-2.27(0.71), 0.002$ \\
\hline Time (month) & $-0.15(0.01),<0.0001$ & $-0.15(0.004),<0.0001$ & $-0.18(0.01),<0.0001$ & $-0.18(0.005),<0.0001$ \\
\hline Female & $0.73(0.70), 0.30$ & $1.91(0.51), 0.0002$ & 1.28 (0.92), 0.17 & $2.14(0.69), 0.002$ \\
\hline Age at baseline & $-0.02(0.02), 0.34$ & -0.02 (0.02), 0.23 & $-0.01(0.02), 0.66$ & $-0.01(0.02), 0.72$ \\
\hline CDAl at baseline & $0.43(0.02),<0.0001$ & $0.43(0.02),<0.0001$ & $0.39(0.02),<0.0001$ & $0.39(0.02),<0.0001$ \\
\hline
\end{tabular}

Adjusted model is adjusted for age, sex, time, and CDAl at baseline.

Bold values indicate statistically significant.

ACPA, anticitrullinated protein antibody; CDAI, Clinical Disease Activity Index; GLMMs, Generalised Linear Mixed Models; RA, rheumatoid arthritis; RF, rheumatoid factor.

were significantly associated with smaller improvement in CDAI over time (table 3). Sensitivity analysis adjusting for other explanatory covariates that were significantly associated with CDAI in the univariate analysis showed similar results (online supplementary table $\mathrm{S} 1$ ).

Using SDAI and DAS28-ESR as alternative disease outcome measures showed a similar significant association between $\mathrm{ACPA}^{\mathrm{pos}} / \mathrm{RF}^{\mathrm{pos}}$ and SDAI improvement but not DAS28-ESR improvement, compared with ACPA ${ }^{\text {neg }}$ / $\mathrm{RF}^{\text {neg }}$ patients (online supplementary Tables S2 and S3).
Association between ACPA/RF status and CDAl components over time

Table 4 summarises the results of the tertiary analysis assessing the association between baseline ACPA/RF status and individual components of CDAI using multivariate GLMM analysis. Compared with $A C P A^{\text {neg }} / \mathrm{RF}^{\text {neg }}$, $\mathrm{ACPA}^{\mathrm{pos}} / \mathrm{RF}^{\mathrm{pos}}$ was significantly associated with greater improvements in tender joint count $(\beta$ coefficient -0.65 ; SE 0.21; $\mathrm{p}=0.002$ ), PtGA ( $\beta$ coefficient -0.48 ; SE

Table 4 Association between ACPA/RF status at baseline and CDAl components over time as using GLMMs

\begin{tabular}{|c|c|c|c|c|}
\hline & \multicolumn{4}{|c|}{ Regression coefficients (standard error), p-value } \\
\hline & \multicolumn{4}{|c|}{ Adjusted models } \\
\hline & SJC-28 & TJC-28 & PtGA & PhGA \\
\hline \multicolumn{5}{|c|}{ ACPA status at baseline } \\
\hline $\mathrm{ACPA}^{\text {neg/RF }}{ }^{\text {neg }}$ & Ref & Ref & Ref & Ref \\
\hline $\mathrm{ACPA}^{\text {neg }} / \mathrm{RF}^{\text {pos }}$ & -0.04 (0.22), 0.84 & -0.09 (0.31), 0.77 & $0.18(0.18), 0.31$ & $0.12(0.17), 0.50$ \\
\hline $\mathrm{ACPA}^{\text {pos }} / \mathrm{RF}^{\text {neg }}$ & $-0.003(0.28), 0.99$ & $-0.43(0.39), 0.28$ & $-0.06(0.23), 0.79$ & $-0.03(0.21), 0.90$ \\
\hline $\mathrm{ACPA}^{\text {pos }} / \mathrm{RF}^{\text {pos }}$ & $-0.18(0.15), 0.22$ & $-0.65(0.21), 0.002$ & $-0.48(0.12), 0.0001$ & $-0.29(0.11), 0.01$ \\
\hline Time (month) & $-0.04(0.001),<0.0001$ & $-0.05(0.001),<0.0001$ & $-0.02(0.001),<0.0001$ & $-0.03(0.001),<0.0001$ \\
\hline Female & 0.58 (0.15), 0.0002 & $0.85(0.22),<0.0001$ & 0.19 (0.13), 0.13 & $0.14(0.12), 0.23$ \\
\hline Age at baseline & 0.001 (0.005), 0.79 & $-0.01(0.01), 0.07$ & -0.001 (0.004), 0.75 & $-0.01(0.004), 0.07$ \\
\hline SJC-28 at baseline & $0.34(0.01),<0.0001$ & - & - & - \\
\hline TJC-28 at baseline & - & $0.41(0.01),<0.0001$ & - & - \\
\hline PtGA at baseline & - & - & $0.43(0.02),<0.0001$ & - \\
\hline PhGA at baseline & - & - & - & $0.42(0.02),<0.0001$ \\
\hline
\end{tabular}

Adjusted model is adjusted for age, sex, time and relevant disease activity measures at baseline.

Bold values indicate statistically significant.

ACPA, anticitrullinated protein antibody; CDAl, Clinical Disease Activity Index; GLMMs, Generalised Linear Mixed Models; PhGA, physician global assessment; PtGA, patient global assessment; RF, rheumatoid factor; SJC-28, 28-joint swollen count; TCJ-28, 28-joint tender count. 
0.12; $\mathrm{p}=0.0001)$ and PhGA ( $\beta$ coefficient -0.29 ; SE 0.11; $\mathrm{p}=0.01$ ) over time but not in swollen joint count (table 4 ).

\section{Subset analysis-association between ACPA/RF status and CDAl over time in patients with ERA}

The subset analysis assessing the association between baseline ACPA/RF status and CDAI over time in patients with early disease onset are shown in table 3. After adjusting for potential confounders, a significant association was observed between both $\mathrm{ACPA}^{\text {pos }} / \mathrm{RF}^{\mathrm{pos}}(\beta$ coefficient -2.27; SE 0.71; $\mathrm{p}=0.002)$ and $\mathrm{ACPA}^{\mathrm{pos}} / \mathrm{RF}^{\text {neg }}(\beta$ coefficient -1.72; SE 1.44; $\mathrm{p}=0.02$ ) statuses and greater improvements in CDAI compared with $\mathrm{ACPA}^{\mathrm{neg}} / \mathrm{RF}^{\text {neg }}$, with slightly higher benefits observed in double-positive patients. Female sex ( $\beta$ coefficient 2.14; SE 0.69; $p=0.002$ ) and higher CDAI at baseline ( $\beta$ coefficient 0.39 ; SE: 0.02 ; $\mathrm{p} \leq 0.0001)$ were also significantly associated with smaller improvements in CDAI over time in this subset cohort (table 3).

\section{Subset analysis-individual association between ACPA and RF status and time to first sustained remission and CDAI}

In multivariate analyses, assessing the individual association between ACPA and RF status with time to first sustained remission and with CDAI over time showed a positive effect of ACPA as a predictor for both achieving sustained remission (HR 1.43; 95\% CI 1.08 to 1.89; $\mathrm{p}=0.01$; online supplementary table $\mathrm{S} 4$ ) and greater improvement in CDAI over time ( $\beta$ coefficient -1.61 ; SE 1.48; $p=0.003$; Online supplementary table S5) after adjusting for potential confounders. No significant effect was observed for neither RF status nor the interaction between ACPA and RF.

\section{DISCUSSION}

In the current study, significant differences were observed in treatment outcomes based on combined ACPA and RF status at baseline with earlier achievement of sustained remission for patients with $\mathrm{ACPA}^{\mathrm{pos}} / \mathrm{RF}^{\mathrm{pos}}$ status and greater improvements in CDAI for both $\mathrm{ACPA}^{\mathrm{pos}} / \mathrm{RF}^{\mathrm{pos}}$ and $\mathrm{ACPA}^{\mathrm{pos}} / \mathrm{RF}^{\text {neg }}$ patients compared with $\mathrm{ACPA}^{\text {neg }} /$ $\mathrm{RF}^{\text {neg }}$ patients. On further investigation, these differences were found to be associated with ACPA status, but not RF, suggesting that ACPA status may be more important in active RA. Investigation of the impact of ACPA positivity on the individual components of CDAI showed that tender joint count, PtGA and PhGA, but not swollen joint count, were affected which could suggest that joint swelling is not the reason for different CDAI scores in ACPA positive and negative patients.

Similar to our study, Aletaha et al showed, in a cross-sectional study, that ACPA positive patients had disease activity that was similar to or lower than that of ACPA negative patients, both in the presence and in the absence of $\mathrm{RF}^{5}$ Miriovsky et al also found in $\mathrm{ACPA}^{\mathrm{pos}} / \mathrm{RF}^{\mathrm{neg}}$ patients that higher ACPA concentration was associated with an increased likelihood of remission. ${ }^{8}$ In contrast, in $\mathrm{ACPA}^{\text {neg }} / \mathrm{RF}^{\mathrm{pos}}$ patients, higher $\mathrm{RF}$ concentration trended towards an inverse association with remission but no significant association was shown. In terms of RF status, Mottonen et al showed that RF positivity was not a significant predictor of achieving disease remission even though it was a significant predictor of structural joint damage. ${ }^{6}$ In contrast to our findings, some investigators ${ }^{49}$ found different conclusions. However, these studies did not investigate the association of ACPA and RF; additional methodological aspects that may have contributed to differences in the findings may include, but not be limited to, the lack of multivariate adjustment, the cross-sectional design, sample size and selection (eg, early patients with RA vs established, active vs all patients with RA, response in clinical trials, etc).

Strengths of the current study include examining a large real-world RA patient population with disease activity (one or more swollen joints) but without strict inclusion criteria and no requirement for high disease activity which may be generalisable to clinical practice. In subset analyses, the data could be compared with various populations, serostatus in four groups and early RA. We explored different measures of disease activity as clinical outcomes including CDAI components. The consistent results of various analyses and two additional multivariate models as sensitivity analysis demonstrate the internal validity of findings.

There may be other unmeasured confounders which may have not been accounted for. Furthermore, we were not able to assess the impact of ACPA/RF status on structural joint damage as this information is not collected in the registry.

Although the association between ACPA positivity and sustained remission and low disease activity was assessed, no causal inference can be made. This is an observational study and is potentially confounded as it is not randomised. Treatment was selected by the treating physician and there could be channelling bias. The study was not designed to look mechanistically at why ACPA and RF positive patients have a better treatment response. It could be from genetic differences (eg, the shared epitope of HLADR4 is far higher in seropositive patients and may affect treatment response, drug distribution and clearance, but this is only speculative). Misclassification of some seronegative patients may occur where some do not have RA but a different disease. Drugs that are tested in RA have $70 \%-80 \%$ of the population as seropositive. The generalisability of trial results mostly reflects the responses of seropositive patients.

\section{CONCLUSIONS}

In summary, combined ACPA and RF positivity may be associated with higher remission rate and greater improvement in disease activity during treatment with antirheumatic medications over time in patients with early and established RA. The magnitude of this association seems to be driven by ACPA status rather than RF status as a similar strong association was found between 
positive ACPA and low disease activity compared with negative ACPA.

\section{Author affiliations}

${ }^{1}$ Department of Medicine, Division of Rheumatology, University of Western Ontario, Saint Joseph's Health Care, Ontario, London, Canada

${ }^{2}$ JSS Medical Research, St-Laurent, Quebec, Canada

${ }^{3}$ Toronto General Hospital Research Institute, University Health Network, Toronto, Ontario, Canada

${ }^{4}$ McGill University, Montreal, Quebec, Canada

${ }^{5}$ Department of Medicine, Division of Rheumatology, Mount Sinai Hospital, Toronto, Ontario, Canada

${ }^{6}$ Southlake Regional Health Centre, Newmarket, Ontario, Canada

${ }^{7}$ Department of Medicine and Institute of Health Policy, Management, and

Evaluation, University of Toronto, Toronto, Ontario, Canada

Acknowledgements The authors wish to acknowledge OBRI-RA investigators.

Collaborators The authors wish to acknowledge OBRI-RA investigators: Ahluwalia V, Ahmad Z, Akhavan P, Albert L, Alderdice C, Aubrey M, Bajaj S, Bensen B, Bhavsar S, Bobba R, Bombardier C, Bookman A, CaretteS, Carmona R, Chow A, Ciaschini P, Cividino A, Cohen D, Dixit S, Haaland D, Hanna B, Haroon N, Hochman J, Jaroszynska A,Johnson S, Joshi R, Kagal A, Karasik A, Karsh J, Keystone E, Khalidi N, Kuriya B, Larche M, Lau A, LeRiche N, Leung Fe, Leung Fr, Mahendira D, Matsos M, McDonald-Blumer H, Mittoo S,Mody A, Montgomery A, Mulgund M, Ng E, Papneja T, Pavlova P, Perlin L, Pope J, Purvis J, Rohekar G, Rohekar S, Ruban T, Samadi N, Shaikh S, Shickh A, Shupak R, Smith D, Soucy E, Stein J, Thompson A, Thorne C, Wilkinson S.

Contributors All authors contributed in the conception or design of the work, revised the work critically and approved the final version of the manuscript. MM and ER conducted the data analysis and drafted the manuscript.

Funding No funding has been provided for this manuscript. OBRI was funded by peer reviewed grants from CIHR (Canadian Institute for Health Research), Ontario Ministry of Health and Long-Term Care (MOHLTC), Canadian Arthritis Network (CAN) and unrestricted grants from: Abbvie, Amgen, Celgene, Hospira, Janssen, Lilly, Merck, Novartis, Pfizer, Roche, Sanofi, \& UCB.

Competing interests No funding has been provided for this manuscript. JP has done research studies and/or consulting for AbbVie, Amgen, BMS, GSK, Lilly, Merck, Novartis, Pfizer, Roche, Sandoz, Sanofi, UCB. ER and JSS: none relevant to this project; employees at JSS Medical Research, a Contract Research Organization. EK has received sources of funding for research from Abbott Laboratories, Amgen, Bristol-Myers Squibb, F. Hoffmann-La Roche, Gilead, Janssen, Lilly Pharmaceuticals, Pfizer Pharmaceuticals, Sanofi-Aventis; has a consulting agreement and is a member of an advisory board for Abbott Laboratories, AstraZeneca Pharma, Biotest, Bristol-Myers Squibb Company, Celltrion, Crescendo Bioscience, F. Hoffmann-La Roche, Genentech, Gilead, Janssen, Lilly Pharmaceuticals, Merck, Pfizer Pharmaceuticals, UCB, Sandoz and received speaker honoraria agreements for Amgen, Abbott Laboratories, Bristol-Myers Squibb Canada, F. Hoffmann-La Roche, Janssen, Merck, Pfizer Pharmaceuticals, Sanofi Genzyme UCB. CT has served in advisory boards for AbbVie, Amgen, Celgene, Lilly, Medexus/Medac, Merck, Novartis, Pfizer and Sanofi; has been a consultant for AbbVie, Centocor, Janssen, Lilly, Medexus/Medac and Pfizer; has been a speaker for Medexus/Medac; has participated in investigatorinitiator studies supported by Amgen and Pfizer and has participated in randomised controlled trials supported by AbbVie, Celgene, CaREBiodam, Novartis and Pfizer. $\mathrm{MM}, \mathrm{AC}$, and $\mathrm{CB}$ are employees at OBRI. OBRI was funded by peer reviewed grants from Canadian Institute for Health Research (CIHR), Ontario Ministry of Health and Long-Term Care (MOHLTC), Canadian Arthritis Network (CAN) and unrestricted grants from Abbvie, Amgen, Celgene, Hospira, Janssen, Lilly, Merck, Novartis, Pfizer, Roche, Sanofi and UCB.

Patient consent Obtained.

Ethics approval All sites had ethics approval to enrol patients. All patients signed informed consent. Ethics approval: REB\# is 07-0729 AE (University of Toronto).

Provenance and peer review Not commissioned; externally peer reviewed.

Open access This is an open access article distributed in accordance with the Creative Commons Attribution Non Commercial (CC BY-NC 4.0) license, which permits others to distribute, remix, adapt, build upon this work non-commercially, and license their derivative works on different terms, provided the original work is properly cited, appropriate credit is given, any changes made indicated, and the use is non-commercial. See: http://creativecommons.org/licenses/by-nc/4.0/

\section{REFERENCES}

1. Aletaha D, Neogi T, Silman AJ, et al. 2010 rheumatoid arthritis classification criteria: an American College of Rheumatology/ European League Against Rheumatism collaborative initiative. Ann Rheum Dis 2010;69:1580-8.

2. Aletaha D, Neogi T, Silman AJ, et al. 2010 Rheumatoid arthritis classification criteria: an American College of Rheumatology/ European League Against Rheumatism collaborative initiative. Arthritis Rheum 2010;62:2569-81.

3. Lindqvist E, Eberhardt K, Bendtzen K, et al. Prognostic laboratory markers of joint damage in rheumatoid arthritis. Ann Rheum Dis 2005;64:196-201.

4. van der Helm-van Mil AH, Verpoort KN, Breedveld FC, et al. Antibodies to citrullinated proteins and differences in clinical progression of rheumatoid arthritis. Arthritis Res Ther 2005; 7:R949-58.

5. Aletaha D, Alasti F, Smolen JS. Rheumatoid factor, not antibodies against citrullinated proteins, is associated with baseline disease activity in rheumatoid arthritis clinical trials. Arthritis Res Ther 2015;17:229.

6. Möttönen T, Paimela L, Leirisalo-Repo M, et al. Only high disease activity and positive rheumatoid factor indicate poor prognosis in patients with early rheumatoid arthritis treated with "sawtooth" strategy. Ann Rheum Dis 1998;57:533-9.

7. Zoto A, Selimi B. The relationship of rheumatoid factor with disease activity in patients with rheumatoid arthritis. Int J Sci Res 2015;4:2319-7064.

8. Miriovsky BJ, Michaud K, Thiele GM, et al. Anti-CCP antibody and rheumatoid factor concentrations predict greater disease activity in men with rheumatoid arthritis. Ann Rheum Dis 2010;69:1292-7.

9. Rönnelid J, Wick MC, Lampa J, et al. Longitudinal analysis of citrullinated protein/peptide antibodies (anti-CP) during 5 year follow up in early rheumatoid arthritis: anti-CP status predicts worse disease activity and greater radiological progression. Ann Rheum Dis 2005;64:1744-9.

10. Barra L, Pope JE, Orav JE, et al. Prognosis of seronegative patients in a large prospective cohort of patients with early inflammatory arthritis. J Rheumatol 2014;41): :2361-9.

11. Manfredsdottir VF, Vikingsdottir T, Jonsson T, et al. The effects of tobacco smoking and rheumatoid factor seropositivity on disease activity and joint damage in early rheumatoid arthritis. Rheumatology 2006;45:734-40. 
Correction: ACPA and RF as predictors of sustained clinical remission in patients with rheumatoid arthritis: data from the Ontario Best practices Research Initiative (OBRI)

Pope JE, Movahedi M, Rampakakis E, et al. ACPA and RF as predictors of sustained clinical remission in patients with rheumatoid arthritis: data from the Ontario Best practices Research Initiative (OBRI). RMD Open 2018;4:e000738. doi: 10.1136/ rmdopen-2018-000738.

The authors want to alert the readers on the updates done for tables 2-3 in the published version.

Open access This is an open access article distributed in accordance with the Creative Commons Attribution Non Commercial (CC BY-NC 4.0) license, which permits others to distribute, remix, adapt, build upon this work non-commercially, and license their derivative works on different terms, provided the original work is properly cited, appropriate credit is given, any changes made indicated, and the use is non-commercial. See: http://creativecommons. org/licenses/by-nc/4.0/.

C Author(s) (or their employer(s)) 2019. Re-use permitted under CC BY-NC. No commercial re-use. See rights and permissions. Published by BMJ.

RMD Open 2019;5:e000738corr1. doi:10.1136/rmdopen-2018-000738corr1

Check for updates 